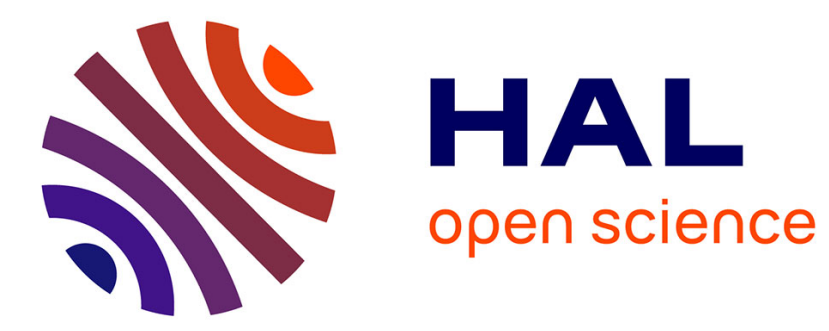

\title{
Chemical vapor composites (CVC)
}

P. Reagan

\section{- To cite this version:}

P. Reagan. Chemical vapor composites (CVC). Journal de Physique IV Proceedings, 1993, 03 (C3), pp.C3-541-C3-548. 10.1051/jp4:1993375 . jpa-00251432

\section{HAL Id: jpa-00251432 https://hal.science/jpa-00251432}

Submitted on 1 Jan 1993

HAL is a multi-disciplinary open access archive for the deposit and dissemination of scientific research documents, whether they are published or not. The documents may come from teaching and research institutions in France or abroad, or from public or private research centers.
L'archive ouverte pluridisciplinaire HAL, est destinée au dépôt et à la diffusion de documents scientifiques de niveau recherche, publiés ou non, émanant des établissements d'enseignement et de recherche français ou étrangers, des laboratoires publics ou privés. 


\title{
Chemical vapor composites (CVC)
}

\section{P. REAGAN}

ThermoTrex Corporation, 85 First Avenue, P.O. Box 8995, Waltham, MA 02254-8995, U.S.A.

\begin{abstract}
The Chemical Vapor Composite, $\mathrm{CVC}^{\otimes}$, process fabricates composite material by simply mixing particles (powders and or fibers) with CVD reactants which are transported and co-deposited on a hot substrate. A key feature of the CVC process is the control provided by varing the density, geometry (aspect ratio) and composition of the entrained particles in the matrix material, during deposition. The process can fabricate composite components to net shape $( \pm 0.013 \mathrm{~mm})$ on a machined substrate in a single step. The microstructure of the deposit is described and several examples of different types of particles in the matrix are illustrated. Mechanical properties of SiC composite material fabricated with $\mathrm{SiC}$ powder and fiber will be presented. Several examples of low cost ceramic composite products will be shown.
\end{abstract}

\section{Introduction}

Industry has a critical need for high-temperature operable ceramic composites that are strong, non-brittle, light weight, and corrosion resistant. Improvements in energy efficiency, reduced emissions and increased productivity can be achieved in many industrial processes if the reaction temperature and pressure are increased. Ceramic composites offer the potential to meet these material requirements in a variety of industrial applications. However, their use is often restricted by high cost. The Chemical Vapor Composite, $\mathrm{CVC}^{1}$, process has the potential to reduce the high costs and multiple fabrication steps presently required for fabrication.

CVC deposition has the potential to eliminate difficult processing problems and greatly increase fabrication rates for composites. With $\mathrm{CVC}$, the manufacturing process can control the composites' density, microstructure and composition during growth. The CVC process:

1. Can grow material 100 times faster than conventional techniques;

2. Does not require an expensive woven preform to infiltrate;

3. Can use high modulus fibers that cannot be woven into a preform;

4. Can deposite composites to tolerances of less than $0.025 \mathrm{~mm}$ on one surface without further machining. 
In CVC a second solid phase is added to the reactant vapor stream of the usual Chemical Vapor Deposition (CVD) system. This solid phase of powder, whisker, and/or fiber is thermochemically stable in the CVD vapor environment and is incorporated into the deposit as a separate species. The ratio of the particulate flux to the vapor flux can be varied over a wide range during deposition, allowing continous control of the composition during deposition.

The CVC process is inherently flexible because of the large number of matrix/particle combinations possible. Only two restrictions apply; the matrix material must be vapor deposited and the particles must be mixable and thermochemically stable in the deposition environment.

\section{Experimental Set-Up}

A schematic of a CVC SiC reactor is shown in Figure 1. This reactor was used to deposit composites with a $\mathrm{SiC}$ matrix and particle reinforcements of powders, whiskers and fibers. The reactor controls the mass flow of both the gas reactants and the particles which are mixed together and injected onto the graphite substrate. During deposition the particles are mixed with $\mathrm{H}_{2}$ and combined with $\mathrm{CH}_{3} \mathrm{SiCl}_{3}$ to form the $\mathrm{SiC}$ composite.

CVC reactors were operated with the substrate either vertical or horizontal and with chamber sizes from $150 \mathrm{~mm}$ diameter $1000 \mathrm{~mm}$ long to $1000 \mathrm{~mm}$ diameter $3000 \mathrm{~mm}$ long. The substrates were heated by induction.

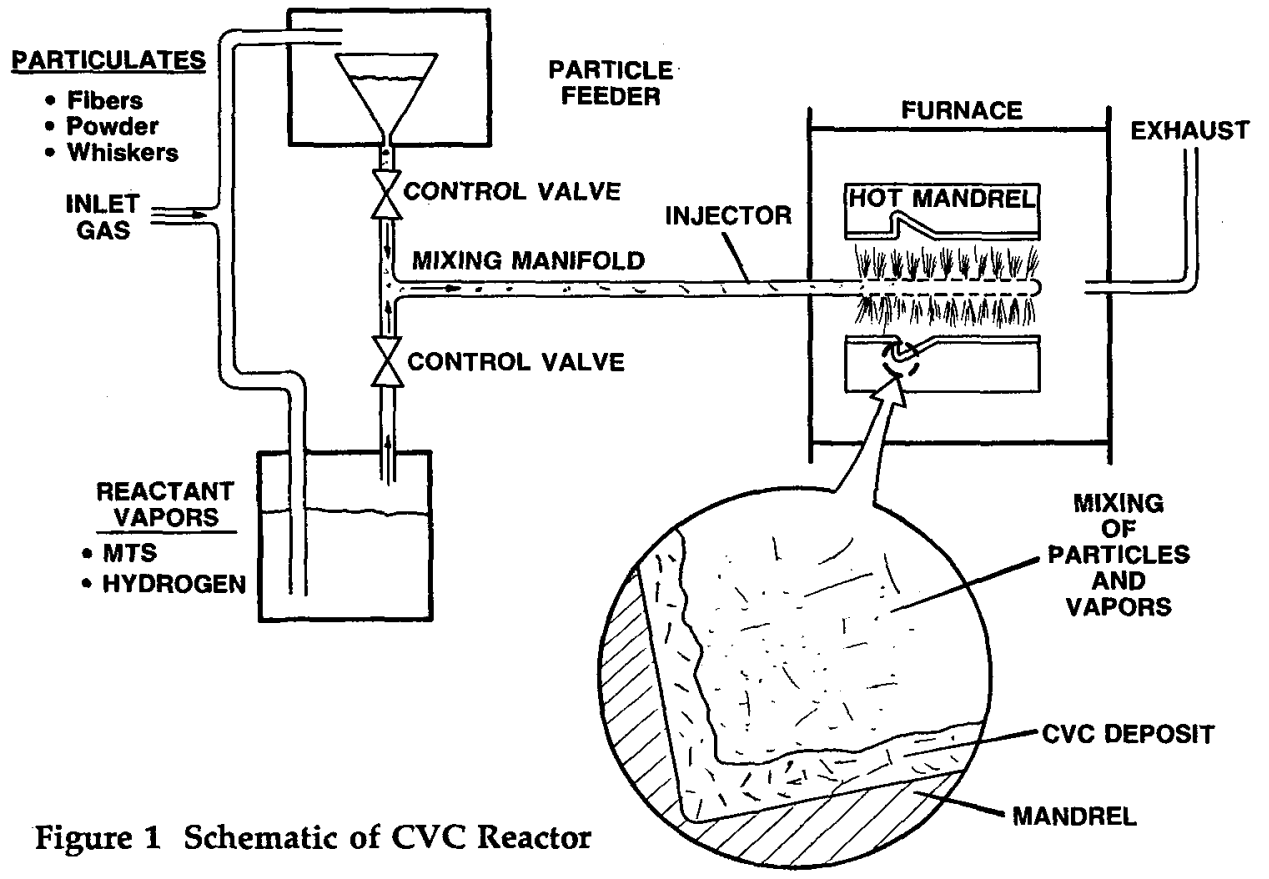




\section{Microstructure}

A key feature of the CVC deposit is the unique grain structure. This grain structure results from a continuously nucleated deposition surface. The particles that come in contact with the deposited surface interrupt the grain growth and generate new nucleation sites. The columnar grain structure usually associated with CVD is absent. It appears that new grains grow from these nucleation points resulting in a smaller grain size. Figure 2 shows that each $\mathrm{SiC}$ particle initiates a new grain. The top surface view of this microstructure in Figure 3 shows each particle surrounded by CVD material. Again, it is apparent from this micrograph that CVD SiC completely encapsulates each SiC particle.

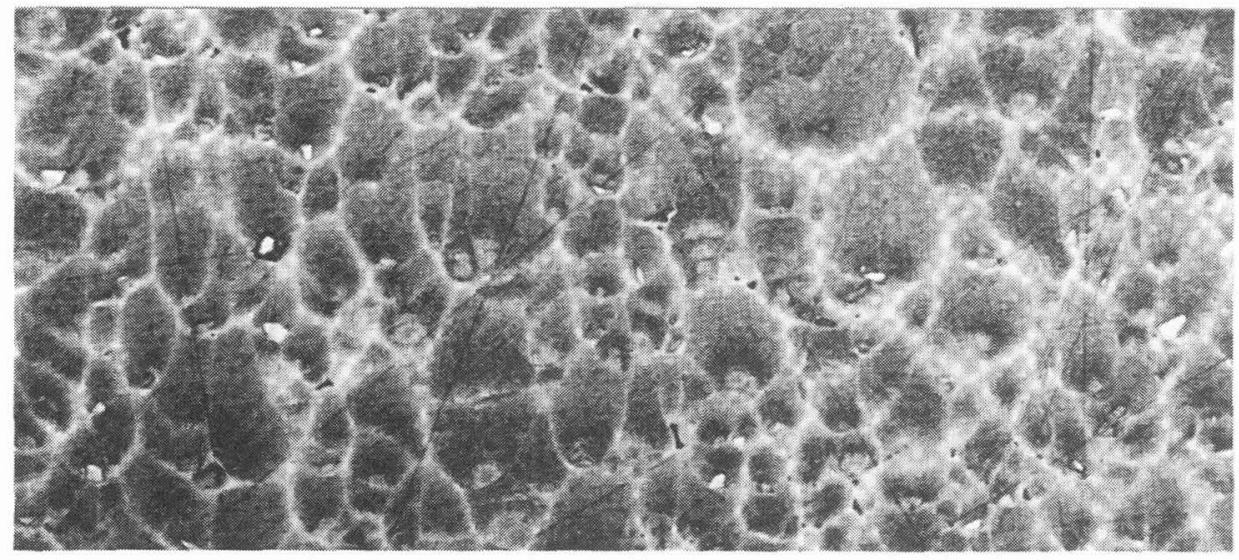

Figure 2 Cross-Section Of CVC SiC Material With SiC Powder - 50 X

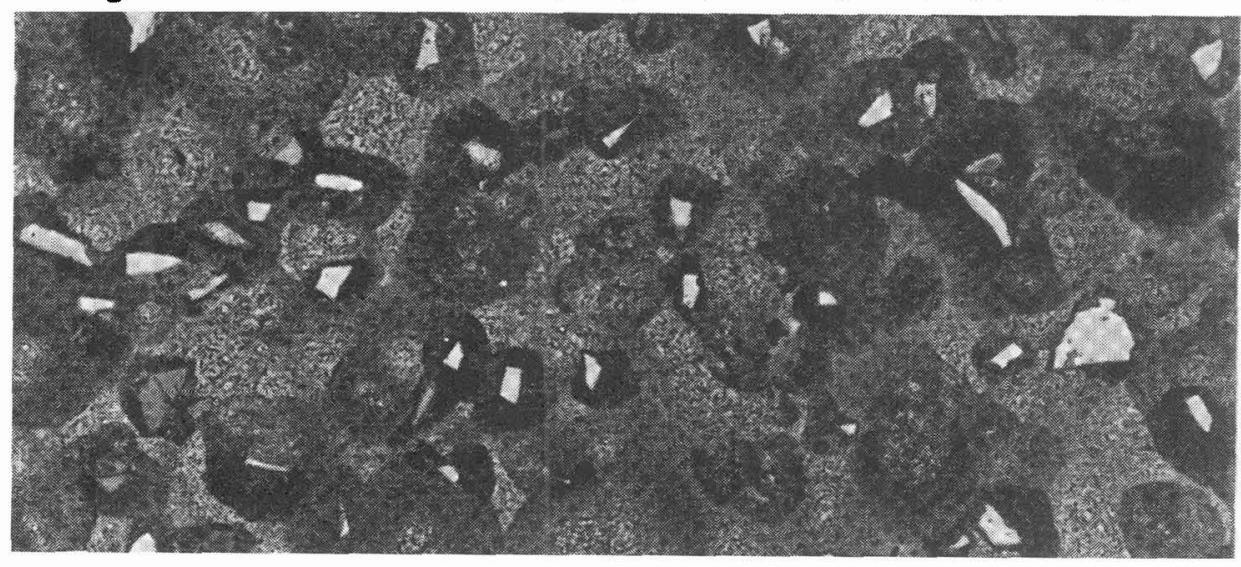

Figure 3 Top View of CVC SiC Material With SiC Powder - 50 X 
CVC structures have also been fabricated with fibers as the reinforcing phase. A SEM of the fracture surface is shown in Figure 4. This composite used $5.0 \mathrm{~mm}$ long Textron $\mathrm{SiC}$-based fibers in a SiC matrix. Note the high degree of fiber pullout indicating the toughness benefit obtained. Carbon fibers ( $2.5 \mathrm{~mm}$ long) were also co-deposited with $\mathrm{SiC}$ as shown in Figure 5. Note that each fiber is completely encapsulated by a matrix of CVD SiC. A small crack in the matrix will only expose a few carbon fibers to the environment. The fibers here are not interconnected as in the case of an infiltrated woven preform. Any environmental attack would therefore be confined to the immediate vicinity of the crack rather than exposing the entire woven preform.

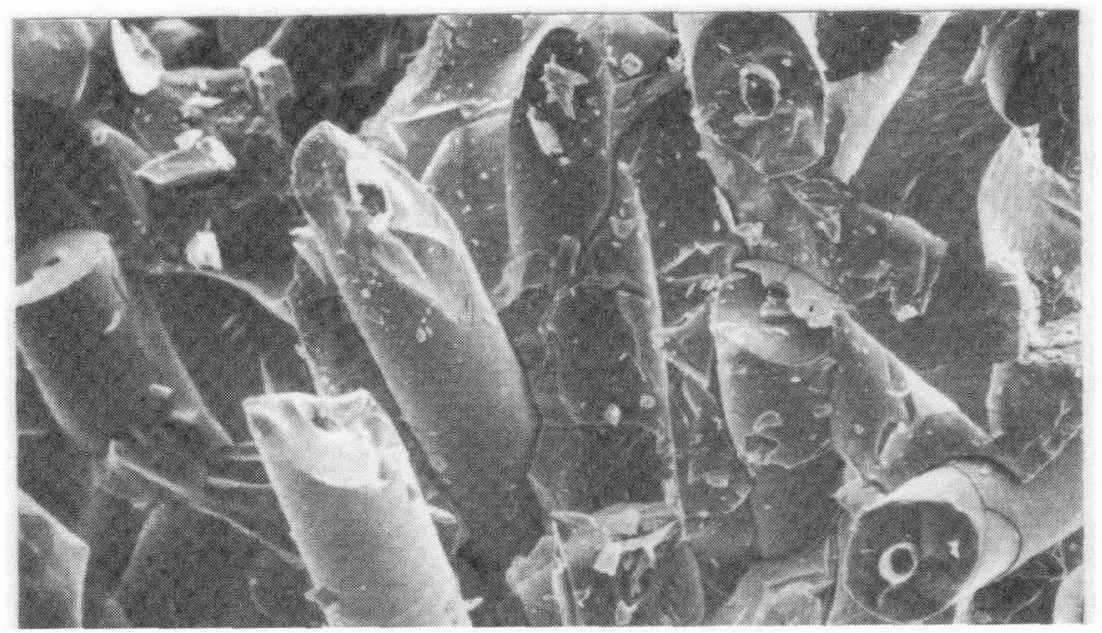

Figure 4 Fracture Surface Of SiC CVC Material With 5 mm Textron Fibers

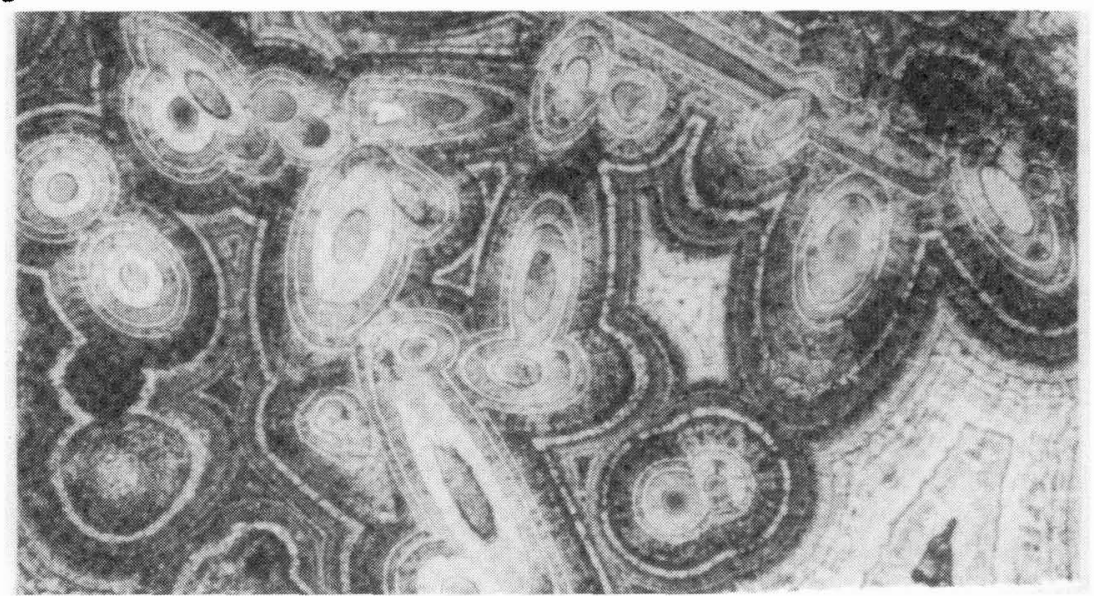

Figure 5 Cross-Section of SiC CVC Material With Carbon Fibers 


\section{Deposition Rate and Density}

A key CVC process parameter that can be continously varied during deposition is the ratio of particle flux to vapor flux.

$$
\text { Ratio }=\frac{\text { Particle flux }}{\text { Vapor flux }}
$$

The flux ratio and particle size and geometry have a dramatic effect on the density of the composite. A low particle flux or ratio will deposit CVD like material that is $100 \%$ dense. If the particle flux and ratio are increased the deposition rate will increase while maintaining a $100 \%$ density. Samples $100 \%$ dense with $40 \mu \mathrm{m}$ SiC powder have been obtained with depositon rates in the order of 0.15 to $0.20 \mu \mathrm{ms}^{-1}$. The properties of this material are summarized in Table 1.

If the particle flux and ratio are further increased the deposition rate will continue to increase but the density of the composite will decrease. The geometry of the particulates also affect the density of the deposit. Despostis $30 \%$ dense with chopped fibers were obtained with deposition rates up to $1.5 \mu \mathrm{ms}^{-1}$. A key feature of the CVC process is the ability to vary the flux ratio during deposition. Figure 6 shows a cross-section of a 25 $\mathrm{mm}$ thick layered ceramic composite structure that was deposited at $1.4 \mu \mathrm{ms}^{-1}$. The process was initiated by depositing a $0.25 \mathrm{~mm}$ thick layer of CVD SiC. Next a composite layer with a high ratio of $\mathrm{SiC}$ Textron fibers was deposited. The addition of the fibers caused the density of the deposit to change from $100 \%$ to $30 \%$. The layering effect was accomplished switching the fiber feeder on and off for 30 minute intervals. Finally, the last deposited surface was sealed off with a $1.3 \mathrm{~mm}$ thick CVC deposit of $\mathrm{SiC}$ with $40 \mu \mathrm{m} \mathrm{SiC}$ powder.

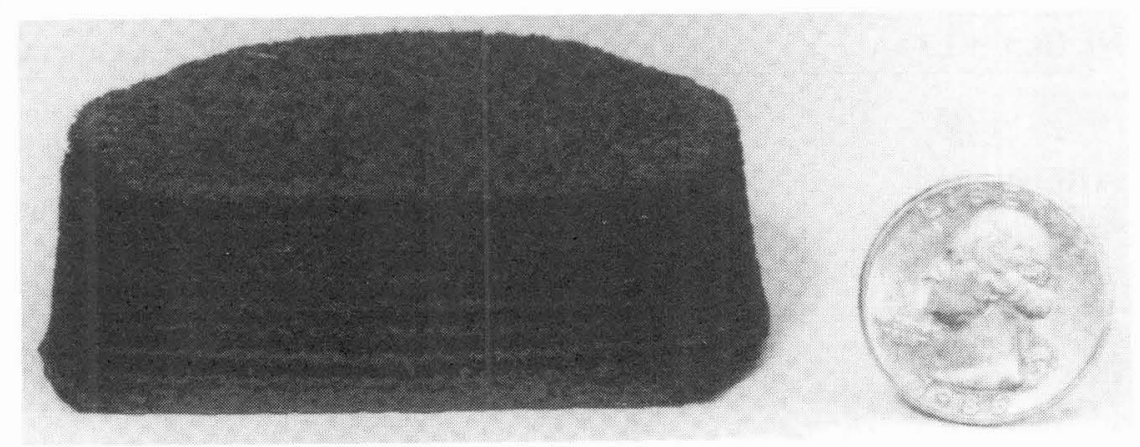

Figure 6 Layered CVC SiC With Textron 5 mm Fibers 


\section{Properties}

Bend bars have been fabricated with the CVC process by mixing SiC powder $(40 \mu \mathrm{m})$ with hydrogen and MTS gases. This CVC material was deposited on the inside of a horizontal tube. The deposition rate of the CVC samples was approximately $0.2 \mu \mathrm{ms}^{-1}$ compared to $0.03 \mu \mathrm{ms}^{-1}$ for CVD. Flexural strength measurements by three-point bend tests at room temperature for 16 bend bars were in the 275-350 MPa range. The density of all samples were $3.22 \pm 0.01 \mathrm{~g} / \mathrm{cm}^{3}$ which indicated minimal porosity in the composite. These broken bend bars were then cycled four times in an air electric oven at $1400 \mathrm{C}$ for 300 hours and again subjected to three-point bend tests. No decrease in strength was observed. Other properties of CVC SiC with $40 \mu \mathrm{m}$ powder was summarized in Table 1.

Table 1

Properties of CVC SiC with $40 \mathrm{~m} \mathrm{SiC} \mathrm{Powder}$

\begin{tabular}{|c|c|c|}
\hline PROPERTIES & $\begin{array}{c}\text { TEMPERATURE } \\
(\mathrm{C})\end{array}$ & VALUES \\
\hline \hline THERMAL EXPANSION & 100 & $3.65 \times 10^{-6}$ \\
& 500 & 4.19 \\
& 1000 & 4.94 \\
\hline YOUNG'S MODULUS & & $450 \mathrm{GPa}$ \\
\hline THERMAL DIFFUSIVITY & 50 & $0.41\left(\mathrm{~cm}^{2} / \mathrm{s}\right)$ \\
& 100 & $0.36\left(\mathrm{~cm}^{2} / \mathrm{s}\right)$ \\
\hline SPECIFIC HEAT & 50 & $0.58 \mathrm{~J} / \mathrm{g} \mathrm{C}$ \\
& 100 & $0.63 \mathrm{~J} / \mathrm{g} \mathrm{C}$ \\
\hline THERMAL & 50 & $.769 \mathrm{watt} / \mathrm{cm} \mathrm{C}$ \\
CONDUCTIVETY & 100 & $.724 \mathrm{watt} / \mathrm{cm} \mathrm{C}$ \\
\hline & & As Deposited \\
& 20 & $275-350 \mathrm{MPa}$ \\
\hline STRENGTH & & After $300 \mathrm{Hours}$ \\
& at $1400 \mathrm{C}$ \\
& 20 & $275-350 \mathrm{MPa}$ \\
\hline
\end{tabular}




\section{CVC Components}

The CVC process has been used to fabricate a variety of composites as shown in Figure 7. All composites shown except for the integrated three mirror component and facing of the ends of the tubes, required no machining. All components were fabricated by depositing on negative graphite substrates. The graphite was removed by grit blasting or by oxidation. Like CVD, the CVC process can replicate the geometry and surface of the substrate. Depending on the types of deposit (inside mandrel deposition or outside mandrel deposition) one surface of the composite will not require any further machining.

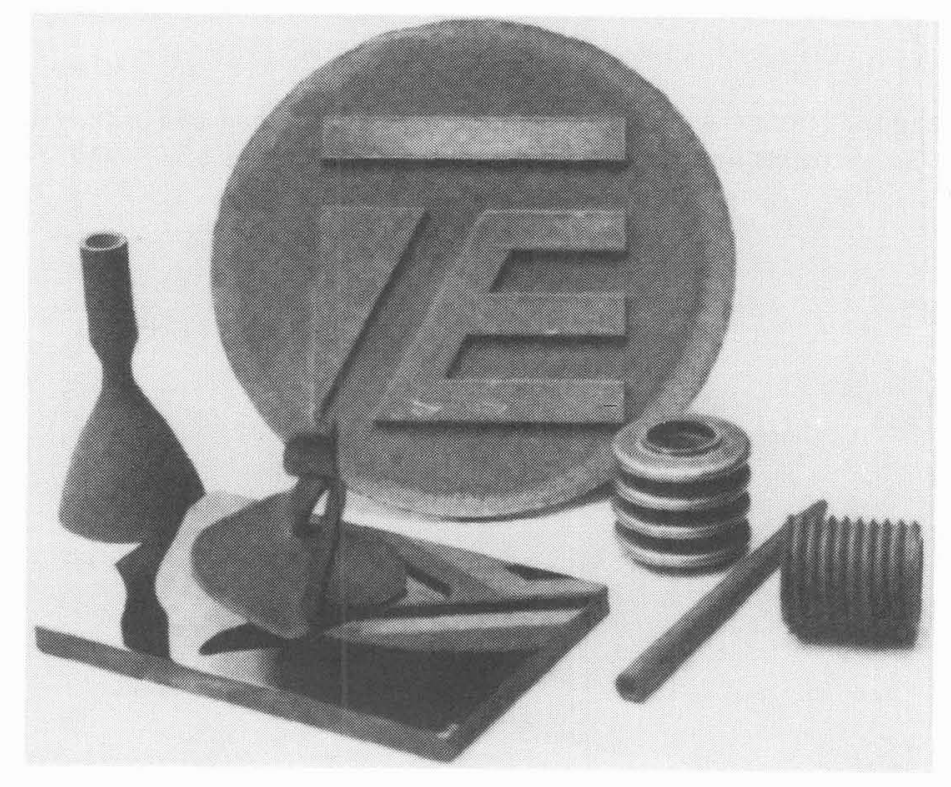

Figure 7 CVC Components left to right - Rocket thruster, Polished mirror, Integrated three mirror system, Thermo Electron logo, Bellows, Thin wall probe, and Threaded tubes 


\section{Conclusions}

$\mathrm{SiC}$ composites with reinforcements of powder and/or fiber have been fabricated by the CVC process. These ceramic composites were fabricated in a single step, with no woven preform, to net shape. The process offers the potential to reduce the manufacturing cost of ceramic composites. The reduced cost of CVC materials could lead to many new applications that were closed to conventional ceramic composites. The increased use of ceramic composites in high temperature industrial applications could have a profound affect on world wide energy usage.

\section{Acknowledgment}

This work was sponsored and supported by Charles Sorrell in, Advance Industrial Concept Division (AICD), U.S. Department of Energy under contract 86XSK445C.

\section{References}

1 Peter Reagan, Nancy A. Scoville, Rebecca Leaf, Method of Forming Composite Articles from CVD Gas Streams and Solid Particles of Fiber. October 13, 1992 U.S. Patent Number 5154862. 